\title{
Haemodynamic Monitoring in the Management Of Cardiogenic Shock in Coronary Care Units
}

\author{
L.A. Schreiber
}

Chief Matron of Education, Johannesburg Hospital

\section{OPSOMMING:}

Die behandeling en versorging van pasiënte wat aan akute miokardinfarksie ly, het die afgelope dekade opvallend verbeter.

Daar het nuwe opvattings i.v.m. die behandeling van kardiogeniese skok ontstaan.

Die onafgebroke waarneming van harthemodinamika deur koronêre sorgverpleegsters het die grootskaalse vooruitgang t.o.v. geneeshere se huidige "koronêre sorg" moontlik gemaak.

Die gebruik van 'n Swan-Ganz-regterhartkateter met vloeibeheerde termoverdunning het hemodinamiese waarneming en meting van pulmonale arteriële druk en pulmonaal-kapillêre wigdruk, sowel as dié van kardiale uitwerp, moontlik gemaak.

The management and nursing care of patients suffering from acute myocardial infarction has changed dramatically over the past decade.

With the establishment of coronary care units offering facilities for cardiac monitoring and staffed with nurses holding a post-basic diploma in intensive nursing, the prevention or effective treatment of life-threatening arrhy thmias became feasible and many have survived as a result of this intensive and skilled care

Another major problem arises from the numerous haemodynamic changes which occur with acute myocardial infarction which often progress to a state of cardiogenic shock with pulmonary oedema and a low cardiac output.

The three basic aims of therapy for the patient with acute myocardial infarction are:

(1) to reduce the increased pulmonary-capillary or wedge pressure, which will lead to pulmonary oedema and

(2) to improve the cardiac output thus improving peripheral perfusion.

(3) The third aim to avoid increasing the imbalance between myocardial oxygen supply and demand, while endeavouring to achieve the above two aims.

There are four major factors which are responsible for increasing myocardial oxygen demands, namely preload, i.e. wedge pressure or pulmonary-capillary pressure. afterload i.e. peripheral vascular resistance or the degree of impedance to ejection by the heart, which is measured clinically as arterial systolic pressure, contractility of the myocardium inotrophy and heart rate (chronotrophy).

Over the last few years new concepts of the treatment of cardiogenic shock have developed and these depend on the manipulation of afterload and preload so that the cardiac output is maintained without an increase in myocardial oxygen demands. The blood flow to vital organs such as the heart, brain and kidneys may therefore be increased without damaging the myocardium.
The patient in cardiogenic shock has suffered major haemodynamic changes which have resulted in increased pulmonary-capillary or wedge pressure and diminished cardiac output. He is critically ill and has slender chance of survival in the absence of haemodynamic monitoring and the meticulous prescription by a cardiologist of the appropriate medication to manipulate and correct the disturbed haemodynamics.

The frequent, "round the clock" monitoring of cardiac haemodynamics by "coronary care" nurses has made it possible for the great forward strides which are being made by physicians in their" "coronary care" today.

Haemodynamic monitoring, using a halloon-tipped, (Swan-Ganz) flow-directed, thermodilution, right heart catheter. has made it possible to measure pulmonary arterial and pulmonary-capillary or wedge pressures as well as the cardiac output.

The catheter may also be used to measure right atrial pressure i.e. central venous pressure and allows blood specimens to be taken from either the right atrium or the pulmonary artery.

This quadruple-lumen catheter (Fig. 1) has one large lumen which terminates at the tip, through which heparinised $0,45 \%$ saline is run. It is through this lumen that the pressure tracings of pulmonary arterial and pulmonary-capillary or wedge pressures are measured (No: 4 in Fig. 1) A second small lumen leads to the little balloon at the catheter tip and allows it to be inflated and deflated (No: 1 in Fig. 1). A third lumen terminates either 20 or $30 \mathrm{~cm}$ (depending on the catheter model) proximal to the catheter tip and so communicates with the right atrium or superior vena cava (No: 3 in Fig 1). The fourth small lumen carries the electrical leads from the thermistor temperature detector, which is positioned on the catheter surface $4 \mathrm{~cm}$ proximal to the tip (No: 2 in Fig. 1.). The body of the catheter is radio-opaque and can be visualised by fluoroscopy. The catheter is introduced via a 


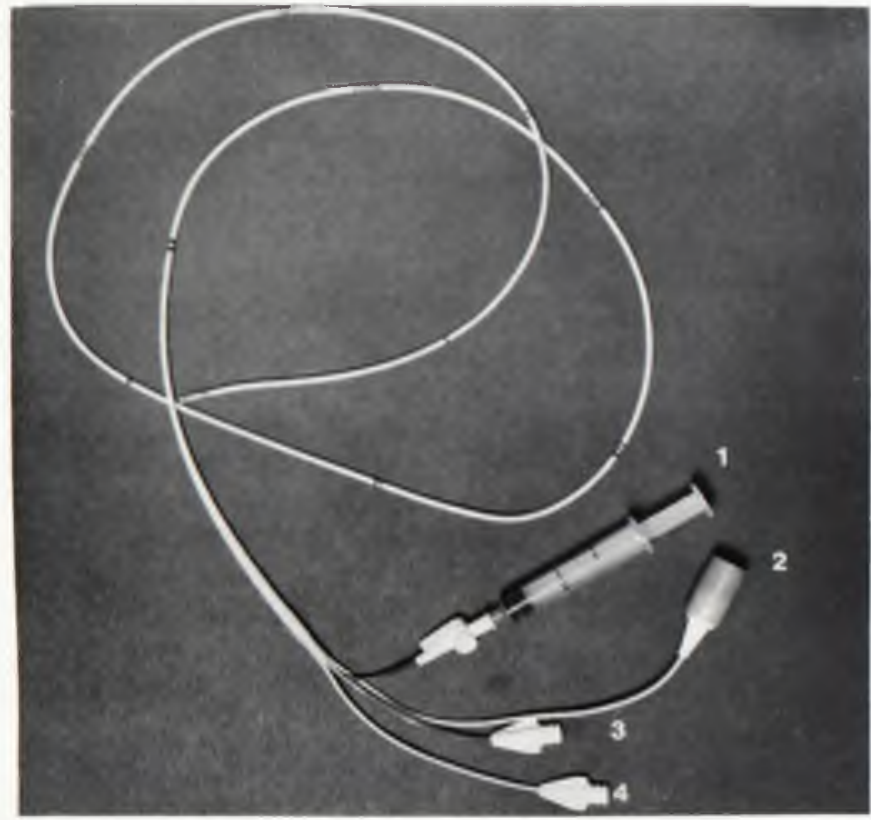

Fig. 1

\section{SWAN-GANZ THERMODILUTION CATHETER WITH QUADRUPLE LUMEN}

(1) Lumen through which balloon is inflated and deflated

(2) Electrical lead from the Thermistor Temperature Detector which plugs into the Cardiac Output Computer

(3) Lumen terminating 20 or $30 \mathrm{~cm}$ proximal to tip i.e. in right atrium through which iced saline is injected

(4) Large lumen terminating at tip, beyond the balloon, through which the infusion is run and through which the pulmonary arterial and pulmonary-capillary wedge pressures are measured.

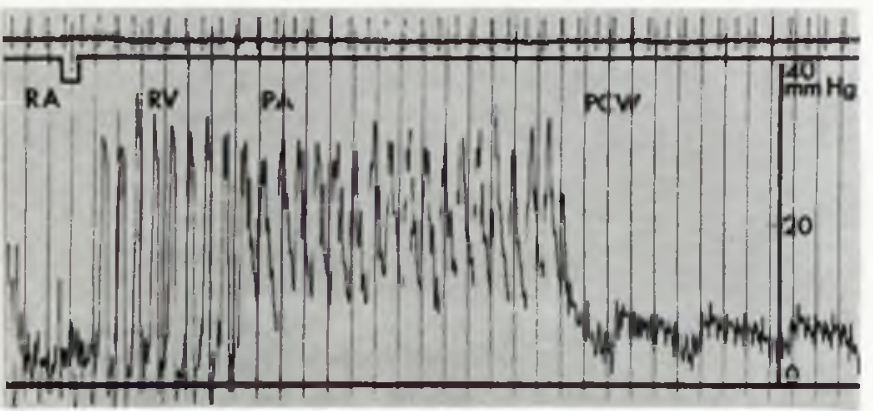

Fig. 2

Continuous pressure recording as the Swan-Ganz Catheter passes through RA-Right Atrium, RV- Right Ventricle, PA- Pulmonary Artery to wedge in a distal pulmonary artery, thus giving PCW- Pulmonary-Capillary Wedge pressure.

peripheral vein and the procedure can be carried out at the bedside without the use of fluoroscopy.

On reaching the superior vena cava or right atrium, the little balloon is partially inflated with air which allows it to be swept along with the blood flow, hence the name flowdirected, right heart catheter.

The catheter is inserted under pressure monitoring control so that the tracing is seen on the monitor screen. (Fig. 2)

As the catheter passes through the right atrium, pressure tracings show a pressure of about $5 \mathrm{~mm} / \mathrm{Hg}$ in a normal subject. A swing from about $30 \mathrm{~mm} / \mathrm{Hg}$ to zero is seen as the catheter passes through the right ventricle, while the tracing shows a swing between about $30 \mathrm{~mm} / \mathrm{Hg}$ and $15 \mathrm{~mm} / \mathrm{Hg}$ as the catheter enters the pulmonary artery. The balloon is now

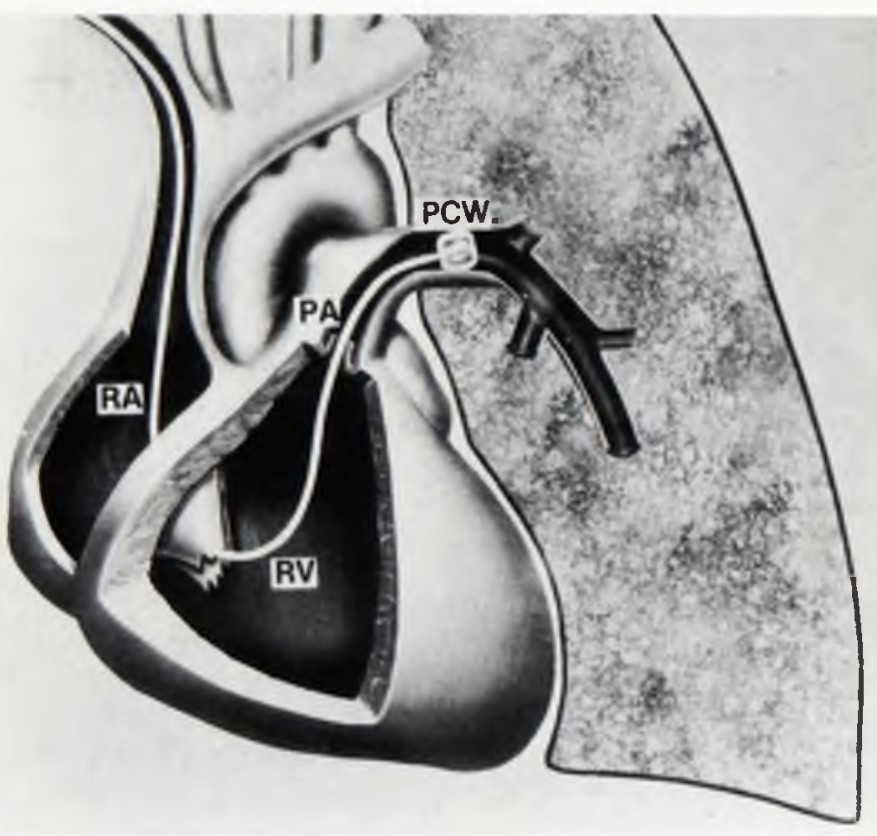

Fig. 3

Swan-Ganz flow directed, Right Heart Catheter in situ showing balloon inflated for Pulmonary-Capillary wedge pressure reading to be taken. RA- Right Atrium, RV- Right Ventricle, PA- Pulmonary Artery, PCW- Pulmonary-Capillary wedge.

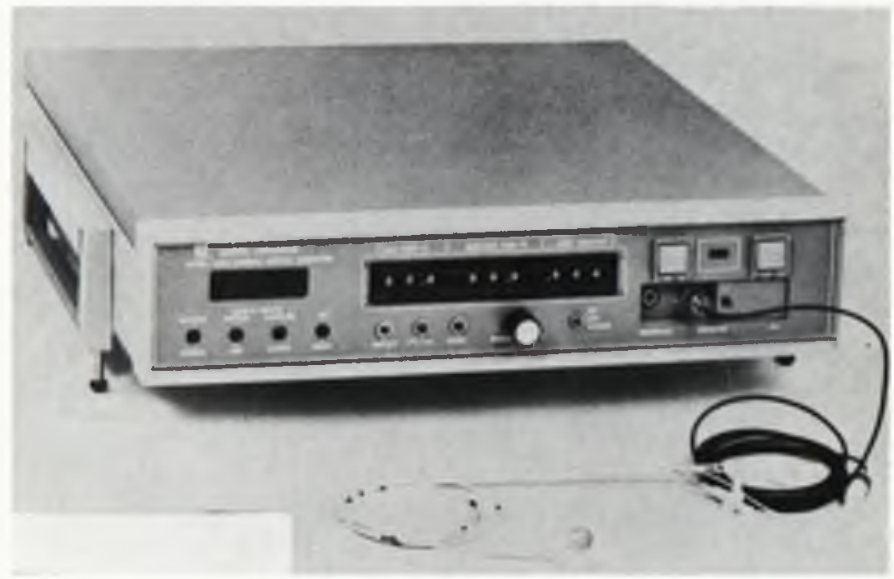

Fig. 4

\section{Cardiac Output Computer}

completely inflated, being filled with the exact volume of air indicated on the catheter, and is allowed to advance to a wedge position, where it becomes impacted in a vessel of the same diameter and occludes it. The pressure reading taken at this stage would reflect the pressure beyond the balloon as the lumen is located at the catheter tip. The pressure beyond the balloon would therefore be that of the pulmonary capillary bed and would thus reflect the pressure in the left atrium and in fact the left ventricular filling pressure. (See Fig. 3).

In a normal subject a wedge pressure of 5 to $12 \mathrm{~mm} / \mathrm{Hg}$ is found, following myocardial infarction, however the pressure may need to be maintained at 14 to $18 \mathrm{~mm} / \mathrm{Hg}$, as optimal ventricular filling and myocardial function occur at this level in the post-infarction heart. 
A wedge pressure of 18 to $20 \mathrm{~mm} / \mathrm{Hg}$ indicates the onset of pulmonary congestion; 20 to $25 \mathrm{~mm} / \mathrm{Hg}$, shows moderate congestion; 25 to $30 \mathrm{~mm} / \mathrm{Hg}$ shows severe congestion while a wedge pressure of more than $30 \mathrm{~mm} / \mathrm{Hg}$, indicates the onset of pulmonary oedema.

It is obvious then that wedge pressure readings which are a reflection of preload, would offer most valuable guidance to the physician who will base his therapy on these pressure readings.

Cardiac output is measured by injecting a known amount of iced saline through the lumen which ends in the right atrium or superior vena cava.

The thermistor temperature detector is located $4 \mathrm{~cm}$ from the tip of the catheter, lying in the pulmonary artery. The iced saline flows out into the right atrium or superior vena cava and cools the blood, hence the name "thermodilution catheter". The resultant change in blood temperature is detected by the thermistor on the surface of the catheter.

The detected change in temperature reaches the cardiac output computer (Fig. 4) via electrical leads from the thermistor. The rectal temperature of the patient forms part of the computed data essential for the thermodilution procedure.

The cardiac output is inversely proportional to the integral temperature change. This allows the cardiac output to be measured as well as the cardiac index and stroke work index to be calculated.

If the stroke work index is less than $20 \mathrm{ml} / \mathrm{m}^{2}$ it is an indication that the patient is suffering from cardiogenic shock, while an index of $10 \mathrm{ml} / \mathrm{m}^{2}$ has been associated with a $90 \%$ mortality. (normal stroke index $40 \pm 7 \mathrm{ml} / \mathrm{m}^{2}$ )

The cardiac output determined by this method is highly accurate and reproducible

\section{CARDIOGENIC SHOCK}

Cardiogenic shock is a state of acute, severe left ventricular failure accompanied by a low cardiac output and high left ventricular filling pressure.

The causes are:

1) most commonly. myocardial infarction with massive left ventricular damage usually in excess of $35 \%$ of the functioning left ventricle;

2) the condition may follow cardiac surgery;

3) it may be precipitated by arrhythmias;

4) Failure in conduction of the impulse;

5) extreme bradycardias;

6) tachycardias eg. paroxysmal atrial tachycardia;

7) it may occur in valvular disease where the cusp of a valve ruptures e.g. the aortic or mitral valve or

8) in rupture of the heart;

9) it can present as a result of myocarditis or cardiac myopathies;

10) it occurs where trauma to the heart results in pericardial tamponade which compresses the heart;

11) Where there is impaired filling of the left atrium as a result of pulmonary embolism associated with reflex ischaemia:

12) in tension pneumothorax, which compresses the yreat veins or the heart itself;

13) it may be seen in the late stages of congestive cardiac failure.

\section{THE CLINICAL PICTLRE}

The cardiac output falls so that the systolic blood pressure drops below $90 \mathrm{~mm} / \mathrm{Hg}$ : the baroreceptors are stimulated so that there is a raised peripheral resistance.

The skin is cold. clammy, pale and often mottled
Cyanosis may be present. The level of consciousness may be altered or there may be some mental impairment. The urinary output is diminished

The pulse may be very slow or very rapid and thready. Pulmonary oedema will develop due to back pressure on the lungs (increased pulmonary capillary pressure) as a result of a failure in the forward flow from the heart (cardiac output). The pressure on the right side of the heart may rise causing a rise in the central venous pressure, but cardiogenic shock with pulmonary oedema can occur without a rise in the central venous pressure. For this reason it is far safer to measure left atrial pressure using a Swan-Ganz flow-directed right heart catheter.

\section{THE MANAGEMENT OF THE PATIENT WITH CAR- DIOGENIC SHOCK}

The management of cardiogenic shock which follows is a somewhat detailed account of the manipulation of the haemodynamic status of the patient by administering drugs according to Swan-Ganz pulmonary arterial wedge pressure readings and thus improving the cardiac output. while at the same lime protecting the myocardium.

With this therapy, the mortality in cardiogenic shock which was in excess of $90 \%$ has been reduced to between $50 \%-60 \%$.

Though some of these patients who survive may be left with a damaged myocardium and are often in chronic hear failure, it is hoped that this may improve in the future.

The initial clinical diagnosis is usually not difficult but it requires confirmation by the measurement of the pulmonary arterial wedge pressure with a Swan-Ganz catheter, as some $10-20 \%$ of patients have a low wedge pressure and will respond simply to fluid administration and cannot therefore be said to be in true cardiogenic shock. The prognosis of this group is much better.

While the left ventricle is much better adapted than the right to coping with pressure. it is still nevertheless more efficient as a volume pump than as a pressure pump. Under circumstances. where the left ventricular muscle mass is acutely damaged. it is unable to cope with the systemic pressure without a significant reduction in stroke volume. The peripheral vascular resistance therefore tends to be high as the baroreceptors tend to maintain the systemic blood pressure at the expense of the cardiac output. Therefore the left ventricle is pumping against an increased afterload.

The afterload is determined mainly by the mean arterial blood pressure which reflects peripheral vascular resistance. but is also dependent on the tension in the walls of the ventricle.

The preload or wedge pressure. refers to the diastolic distension of the left ventricle just prior to the onset of systole. It depends on left ventricular volume and end diastolic pressure. both of which tend to go up with left ventricular failure.

The effect of the increased preload is to increase left ventricular contraction by the Starling principle, ${ }^{*}$ but the consequence of raised end diastolic pressure is pulmonary congestion because this pressure is obviously transmitted back to the left atrium, and to the pulmonary veins.

* Starling 's law of the heart states that the strength of cardiac contraction is proportional to myocardial fibre length (or left ventricular volume) at the onset of contraction.

The normal left ventricular end diastolic pressure is up to $12 \mathrm{~mm} / \mathrm{Hg}$, and pulmonary congestion is usually not 
apparent until the left atrial pressure esceeds $18-20 \mathrm{~mm} / \mathrm{Hg}$ This pressure can be measured by the Swan-Ganz catheter.

If left ventricular diastolic pressure rises significantly higher than $20 \mathrm{~mm} / \mathrm{Hg}$ the left ventricular output may be further reduced by overstretching the myocardial fibres.

The cardiac output is determined by the preload and contractile state of the myocardium and the afterload. A damaged myocardium is less compliant and requires a greater filling pressure than the normal heart, therefore a moderate increase in preload i.e. 12 to $14 \mathrm{~mm} / \mathrm{Hg}$ and greater contractility will tend to increase the cardiac output, whereas a higher afterload will tend to decrease it.

The older forms of treatment of cardiogenic shock concentrated on using drugs to increase the contractility of the myocardium and many of these such as nor-adrenaline also actually increased the afterload by increasing peripheral vascular resistance. These effects tend to be deleterious, for by increasing myocardial oxygen demands, they tend to iilcrease the size of the infarction and are therefore selfdefeating.

Isoprenaline also markedly increases the myocardial oxygen demands because of its positive inotropic and chronotropic effects.

The most important means of treatment then, is to reduce the afterload or peripheral vascular resistance by means of vaso-dilator drugs.

Sodium nitroprusside solution by intravenous infusion is almost the most useful as it has a very rapid onset and short duration of action and can be easily controlled. It can however only be used in an intensive care unit where adequate monitoring facilities are present and can of course be disastrous if used inappropriately. It is appropriate in patients with high left ventricular filling pressures and reduced cardiac output and with a high peripheral vascular resistance.

Under these circumstances, even if the systemic blood pressure is on the low side, it will not drop further and may even increase with the administration of nitroprusside. The reason for this is that the load on the left ventricle is decreased as the peripheral resistance is reduced and the stroke volume tends to increase, therefore as the cardiac output rises the blood pressure is maintained.

Preload reduction is desirable in addition in many cases. Reducing preload will reduce pulmonary congestion and improve oxygenation and will also reduce myocardial stretch and improve sub-endocardial blood flow.

By the reduction of end diastolic volume and diameter, afterload will at the same time be reduced and many of the drugs used will additionally cause some peripheral arteriolar dilation. Therefore the concept of preload on its own is a little artificial. Nitroglycerin and its derivatives have been the most effective drugs in this regard.

Sublingual glyceral trinitrate, which is known as T.N.T will drop preload, but only for a short time and somewhat uncontrollable. Intravenous nitro-glycerin has been very useful but is used less now owing to problems of supply of the drugs.

Oral isosorbide dinitrate (Isordil) has been useful as it is effective and has a duration of action of at least four hours.

It should be noted that sodium nitroprusside does have the action of reducing preload by dilating the venous capacitance vessels as do the T.N.T. preparations, but to a lesser extent.

Other vasodilators may be used and may be given orally such as hydralazine and prazosin (minipress). These have the advantage of being able to be given orally and it may be possible to wean a patient from intravenous nitroprusside to an oral vaso-dilator, sometimes with the addition of isosorbide.

Diuretics are still important and furosemide (Lasix) is still necessary in almost all patients.

Furosemide reduces pulmonary capillary pressure within minutes of administration probably due to a change in the distribution of venous blood and a venous dilatation, thus reducing preload. A further drop in pulmonary-capillary pressure follows some hours later due to the diuretic effect of the drug. Even when renal shut-down has occurred, the drug is most beneficial for its effect on reducing pulmonary capillary pressure, the blood being dispersed to the dilated venous capacitance vessels.

Digitalis is not usually used in the acute phase of myocardial infarction as the increase in contractility may extend the area of infarction, but it may be useful later on with a dilated, failing ventricle. If it helps to reduce ventricular cavity size, the net effect on myocardial oxygen demand may be beneficial.

Dopamine hydrochloride (Intropin) is presently the most usefulcatecholamine derivative. It has less tendency to cause tachycardia than isoprenaline and at low dosage tends to dilate the renal vascular bed and improve renal blood flow. In higher dosage it increases total peripheral vascular resistance.

Glucagon is still useful occasionally, as a virtually pure inotropic agent with little effect on heart rate.

Isoprenaline is now rarely if ever used for cardiogenic shock except in some patients with mitral valve disease and high pulmonary vascular resistance and those with pulmonary embolism who are in shock. It tends to dilate the pulmonary vasculature and is therefore still sometimes used after cardiac surgery.

Morphia may be a very useful drug for both its pain-killing and anxiety-relieving properties and for the fact that it reduces preload by venous dilatation. It remains therefore a drug of choice in acute left ventricular failure.

Ventilation is occasionally required for patients in severe pulmonary oedema where oxygenation is a problem.

The use of the Swan-Ganz catheter allows one to make the diagnosis of cardiogenic shock with confidence as well as to monitor therapy. An additional advantage is the ability to diagnose remedial mechanical defects, such as rupture of the interventricular septum or severe mitral regurgitation.

It is important if any surgically remedial disorder is present that this should be treated if possible. For example a patient with a ruptured aortic valve with severe aortic regurgitation may present with cardiogenic shock and there would be no hope unless this was recognised and he was sent for urgent aortic valve replacement. To some extent the same may apply with aortic stenosis and mitral regurgitation.

The use of intra-aortic balloon counterpulsation in cardiogenic shock is generally restricted to those patients in whom surgery is contemplated or in post-operative cardiac patients. It has been disappointing in the treatment of cardiogenic shock related to a large loss of functioning left ventricle. The patient often improves dramatically while on counter-pulsation, but is usually not able to be weaned from the pump.

The use of preload and afterload reduction has in fact, largely replaced the need for counterpulsation. The 